Disclosure of Interests: José Alexandre Mendonça Speakers bureau: Novartis, Janssen, Bristol, UCB, Isabella Siste de Almeida Aoki: None declared, Caique Chagas Cavuto: None declared, Vânia Aparecida Leandro-Merhi: None declared, José Luis Braga de Aquino: None declared DOI: 10.1136/annrheumdis-2021-eular.3269

\section{AB0799 DO WE OVERDIAGNOSE SERONEGATIVE RHEUMATOID ARTHRITIS? - THE ROLE OF MUSCULOSKELETAL ULTRASOUND IN CLARIFYING SERONEGATIVE INFLAMMATORY ARTHRITIS}

D. Esperança Almeida ${ }^{1}$, E. Costa ${ }^{1}$, F. Guimarães ${ }^{2}$, A. S. Pinto ${ }^{3}$, H. Parente ${ }^{2}$, S. Azevedo ${ }^{2}$, J. Rodrigues ${ }^{2}$, J. Tavares-Costa' ${ }^{2}$, C. Afonso ${ }^{2}$, D. Faria ${ }^{2}$, M. Cerqueira ${ }^{1}$, F. Teixeira ${ }^{2}{ }^{1}$ Hospital de Braga, Serviço de Reumatologia, Braga, Portugal; ${ }^{2}$ Unidade Local de Saúde do Alto Minho, Serviço de Reumatologia, Ponte de Lima, Portugal; ${ }^{3}$ Unidade Local de Saúde da Guarda, Serviço de Reumatologia, Guarda, Portugal

Background: Several data indicate that seronegative rheumatoid arthritis (RA-) and seropositive RA (RA+) may have different mechanisms and prognosis, being well established that rheumatoid factor (RF) and anti-citrullinated peptide antibodies (ACPA) have diagnostic and prognostic value. Several conditions, like peripheral spondyloarthritis $(\mathrm{SpA})$, psoriatic arthritis or crystal-related arthropathies may mimic the presentation of RA. Mechanisms and treatment of each of these conditions differ significantly. The authors speculate that RA- may be overdiagnosed in the setting of seronegative chronic inflammatory arthritis and that musculoskeletal ultrasound (US) may help us to better classify these patients through the identification of characteristic lesions of the mentioned diseases.

Objectives: To compare the frequency of US lesions found in joints and entheses between RA- and RA+ patients.

Methods: Cross-sectional study: systematic US evaluation of ten joints, twelve entheses and both flexor and extensor tendons of four fingers (Table 1) in consecutive RA- patients. RA+ patients matched for sex and age were recruited. RA- patients included met every of the following criteria: history of chronic polyarthritis, RF and ACPA negativity, no extra-articular features of SpA or RA nor family history of SpA, no suspected crystal-related arthritis.

Results: Twenty-one RA- patients were included and twenty RA+ patients were recruited as controls. No differences between groups were found in sex, age, body mass index, time of disease evolution or use of biological therapy.

RA- patients had a significantly higher number of entheseal structural and/or inflammatory lesions than RA+ patients (median 2.0 vs. $0.5, \mathrm{U} 111.5, \mathrm{p}=.008^{\star *}$ ), with triceps enthesitis being significantly more frequent in RA- patients $\left(p=.036^{*}\right)$. In total, $18.7 \%$ of RA- entheses had enthesitis lesions vs. only $8.3 \%$ of RA+ entheses. One RA- patient had ultrasonographic features of dactylitis which was not clinically evident.

As expected, considering the role of RF and ACPA in erosive RA, RA- patients had a significantly lower number of joints with erosions compared to RA+ patients (median 0.0 vs. $3.0, \cup 64.5, p<.001^{\star \star \star}$ ), with significant differences in every considered joint. Erosions were found in $6.7 \%$ of RA- joints vs. $32.0 \%$ RA+ joints. Additionally, two RA- patients had hyperechogenic foci in knee cartilage or carpal fibrocartilage suggestive of calcium pyrophosphate deposition.

Table 1. Comparative frequency of ultrasound lesions found in joints and entheses of RA- and RA+ patients.

\begin{tabular}{|c|c|c|c|}
\hline & $\begin{array}{c}\text { RA- } \\
(n=21)\end{array}$ & $\begin{array}{c}\mathrm{RA}+ \\
(\mathrm{n}=20)\end{array}$ & $p$-value \\
\hline $\begin{array}{l}\text { Mdn number of ENTHESES with any lesion } \\
\text { per patient } \pm \text { IQR }\end{array}$ & $2.0 \pm 3.0$ & $0.5 \pm 2.0$ & $.008^{\star \star}$ \\
\hline Triceps - n (\%) & $8(38.1 \%)$ & $2(10.0 \%)$ & $.036^{*}$ \\
\hline Quadriceps - n (\%) & $9(42.9 \%)$ & $6(30.0 \%)$ & .393 \\
\hline Superior patellar $-\mathrm{n}(\%)$ & $4(19.0 \%)$ & $1(5.0 \%)$ & .169 \\
\hline Inferior patellar - n (\%) & - & - & - \\
\hline Achilles $-\mathrm{n}(\%)$ & $9(42.8 \%)$ & $4(20.0 \%)$ & .116 \\
\hline Plantar fascia $-\mathrm{n}(\%)$ & $5(23.8 \%)$ & $1(5.0 \%)$ & .089 \\
\hline DACTYLITIS $-2^{\text {nd }}+5^{\text {th }}$ finger $-\mathrm{n}(\%)$ & $1(4.8 \%)$ & - & - \\
\hline Mdn number of joints with EROSIONS per patient \pm IQR & $0.0 \pm 1.0$ & $3.0 \pm 3.0$ & $<.001^{\star \star \star}$ \\
\hline Ulnar styloid process - $\mathrm{n}(\%)$ & $5(23.8 \%)$ & $11(55.0 \%)$ & $.041^{\star}$ \\
\hline Metacarpophalangeal $2-n(\%)$ & $3(14.3 \%)$ & $11(55.0 \%)$ & $.006^{\star \star}$ \\
\hline Metacarpophalangeal $5-\mathrm{n}(\%)$ & $1(4.8 \%)$ & $10(50.0 \%)$ & $.001^{\star \star}$ \\
\hline Metatarsophalangeal $1-\mathrm{n}(\%)$ & - & $3(15.0 \%)$ & - \\
\hline Metatarsophalangeal $5-\mathrm{n}(\%)$ & $3(14.3 \%)$ & $11(55.0 \%)$ & $.006^{\star \star}$ \\
\hline $\begin{array}{l}\text { CHONDROCALCINOSIS - triangular fibrocartilage + } \\
\text { knee }-n(\%)\end{array}$ & $2(9.5 \%)$ & - & - \\
\hline DOUBLE CONTOUR - any joint $-\mathrm{n}(\%)$ & - & - & - \\
\hline
\end{tabular}

RA- - seronegative rheumatoid arthritis; RA+ - seropositive rheumatoid arthritis Mdn - median; IQR - interquartile range; $\mathrm{n}(\%)$ - absolute number (percentage) of patients with the indicated lesion.
Conclusion: We found that some patients diagnosed with RA- had, in fact, ultrasonographic features of different diseases, namely enthesitis/dactylitis and crystal deposition. These data suggest that RA- may be overdiagnosed in clinica practice. Systematic US evaluation of joints and entheses may provide valuable diagnostic information in patients with chronic inflammatory seronegative arthritis and improve patient care.

Disclosure of Interests: None declared

DOI: 10.1136/annrheumdis-2021-eular.3588

\section{$\mathrm{AB} 0800$ \\ HEMATOLOGICAL MARKERS OF SYSTEMIC INFLAMMATION IN PATIENTS RHEUMATOID ARTHRITIS (RA) AND SPONDYLOARTHRITIS (SPA)}

B. Targonska-Stepniak ${ }^{1}$, K. Grzechnik ${ }^{2}$, M. Majdan ${ }^{1} .{ }^{1}$ Medical University of Lublin, Rheumatology and Connective Tissue Diseases, Lublin, Poland; ${ }^{2}$ Samodzielny Publiczny Szpital Kliniczny nr 4, Rheumatology and Connective Tissue Diseases, Lublin, Poland

Background: An appropriate assessment of disease activity is essential in the management of patients with chronic inflammatory joint diseases, rheumatoid arthritis (RA) and spondyloarthritis (SpA). Hematological parameters [Neutrophil-To-Lymphocyte (NLR), Platelet-To-Lymphocyte (PLR) and Monocyte-ToLymphocyte (MLR) ratios] have been demonstrated to be good, promising indicators of systemic inflammation status in different diseases, additionally to conventional inflammatory markers [erythrocyte sedimentation rate (ESR), C-reactive protein $(\mathrm{CRP})]$. However results remain conflicting in rheumatic patients.

Objectives: The goal of the study was to determine the role of NLR, PLR, MLR in assessing inflammatory disease activity and to compare the biomarkers in RA and SpA patients.

Methods: An observational study was conducted in patients with RA and SpA (ankylosing spondylitis and psoriatic arthritis) treated in the Department of Rheumatology and Connective Tissue Diseases, Medical University of Lublin, Poland. Demographic and clinical information was obtained through structured interview, review of medical records and laboratory tests. The following disease activity and functional scores were registered: CRP and ESR levels, swollen and tender joints counts (SJC, TJC), DAS28 (ESR), HAQ, BASDAI, BASFI, patient global assessment (PtGA) and physician global assessment (PGA) rated on a visua analogue scale (VAS).

The study group consisted of 95 patients (58 women, 37 men), with the mean (SD) age 45.4 (9.9), disease duration 10.0 (8.4) years. There were $58(61.1 \%)$ patients with RA (44 women, 14 men) and 37 (38.9\%) patients with SpA. The mean age and disease duration were statistically not different in both patients' groups. The mean (SD) DAS28 was 4.21 (1.8) in RA patients; in SpA patients BASDAI 4.9 (2.6) and BASFI 5.0 (2.8).

Results: In the whole group (95 patients) and in the SpA group, we found positive correlations between the PLR value and the following parameters CRP, ESR between NLR and CRP, ESR; between MLR and CRP. In the RA group positive correlations were observed between PLR and CRP, ESR; NLR and CRP; MLR did not correlate with CRP and ESR.

In RA patients, there were statistically significant correlations between values of PLR and DAS28 $(r=0.356, p=0.006)$, TJC $(r=0.308, p=0.02)$, SJC $(r=0.318$ $p=0.016)$, PtGA $(r=0.372, p=0.008)$. No significant correlation was found between NLR, MLR and other disease activity scores.

In SpA patients, we found a significant correlation between NLR and PtGA $(r=0.488, p=0.04)$. No significant correlations were found between NLR, PLR, MLR and BASDAI, BASFI.

The group of RA patients as compared with SpA, was characterized by significantly higher value of PLR [respectively 207.8 (94.0) vs 169.9 (77.7), $p=0.04$ ] In turn, SpA patients compared with RA, were characterized by unfavorable metabolic parameters: higher atherogenic index [respectively $4.03(0.8)$ vs 3.57 (1.1), $p=0.03$ ], lower HDL-cholesterol [47.4 (10.7) vs 56.1 (16.4) mg/dl $(p=0.006)$; higher serum uric acid [5.6 (1.2) vs $4.5(1.4) \mathrm{mg} / \mathrm{dl}(\mathrm{p}=0.0001)]$, higher waist measurement [96.1 (14.2) vs 85.9 (11.5) cm ( $p=0.0003)$.

Conclusion: In our study we found, that in patients with RA, PLR was associated with both clinical and inflammatory markers of disease activity; in SpA patients NLR, PLR and MLR were associated with conventional inflammatory markers (CRP, ESR). Hematological inflammatory biomarkers may reflect disease activity and could represent potential parameters to evaluate disease activity not only in $\mathrm{RA}$, but also in SpA.

Disclosure of Interests: Bozena Targonska-Stepniak Speakers bureau: Berlin-Chemie/Menarini, KRKA, Medac, Santen, Krzysztof Grzechnik: None declared, Maria Majdan Speakers bureau: Roche, Medac DOI: 10.1136/annrheumdis-2021-eular.3942 